\title{
Fatigue life of an anchored blind-bolt loaded in tension
}

\author{
Walid Tizani ${ }^{\mathrm{a}}$, Norashidah Abd Rahman ${ }^{\mathrm{b}}$ and Theodoros Pitrakkos ${ }^{\mathrm{a}}$ \\ ${ }^{a}$ Department of Civil Engineering, The University of Nottingham, UK \\ ${ }^{b}$ Faculty of Civil and Environmental Engineering, Universiti Tun Hussein Onn Malaysia, Johor, Malaysia
}

\begin{abstract}
This paper investigates and reports on the fatigue behaviour of a novel blind-bolt system termed the Extended Hollo-bolt (EHB). The new blind-bolt is a modified version of the standard Lindapter Hollo-bolt, and its application relates to the construction of bolted, moment-resisting connections between open profile beams and concrete-filled tubular columns. The fatigue behaviour of the system is studied on the basis of constant amplitude loading tests, with a total of 56 experiments being reported. The specimens were subjected to tensile loading for various stress ranges, with the repeated load being selected relative to the design yield stress of the blind-bolt's internal shank. The influence of testing frequency and strength of concrete infill is also examined. An analysis of the results indicates that an increase in the concrete strength can increase the fatigue life of the EHB system. Within the tested range, the failure mode of the EHB under repeated loading was found to be due to internal bolt shank fracture, a mode which is consistent with its monotonic behaviour and also comparable with standard bolt-nut-washer systems behaviour. The experimental results (S-N data) were further compared with the Eurocode 3 Part 1-9 guidelines. The fatigue design strength of the anchored EHB blind-bolt is found to be adequately represented by the current specification detail Category 50 that is provided for standard bolting systems.
\end{abstract}

Keywords: blind-bolt; tubular connections; fatigue; frequency; stress range. 


\section{Nomenclature}

$d_{b} \quad$ nominal bolt diameter size

$E_{b} \quad$ bolt Young's modulus of elasticity

$f_{c u, a} \quad$ actual compressive cube strength of concrete (on the day of testing)

$f_{c u, n} \quad$ nominal compressive cube strength of concrete

$f_{y b} \quad$ bolt nominal design stress

$f_{y b, a} \quad$ bolt actual yield strength

$f_{u b, a} \quad$ bolt actual ultimate strength

$N_{f} \quad$ number of cycles to failure

$\Delta_{\sigma} \quad$ stress range

$\Delta \sigma_{a} \quad$ actual stress range

$\Delta \sigma_{n} \quad$ nominal stress range

$\Delta \sigma_{C} \quad$ detail category

$\Delta \sigma_{D} \quad$ constant amplitude fatigue limit

$\Delta \sigma_{L} \quad$ cut off limit 


\section{Introduction}

The use of structural hollow members as columns in steel construction is very attractive to architects and structural engineers. This is mainly due to the aesthetically pleasing appearance that the profiles have to offer. From a structural point of view, it is also generally accepted that the combination of hollow section columns and open profile beams can offer many advantages [1]. Their use, however, is inhibited by problems in establishing structural connections with other members. The application of traditional bolts - that are typically used to form bolted connections between open profile sections - cannot be utilised in the case of hollow columns. This is because the technique requires access to the inside of the section to facilitate tightening. To overcome this complexity, early development included the provision of intense welding among members, as well as the use of additional components, such as gusset plates and brackets in order to construct such joints. But, arguably, these methods are not efficient solutions; for practical and aesthetic reasons.

More recent development in connection technology has introduced a fastening system that does not require access to both sides of the connection being formed; blind fasteners. Several types of blind-bolts have been developed over the years for use in a number of engineering fields. Commercially available examples include the Flowdrill, the Huck, the AJAX Oneside, and the Lindapter Hollo-bolt (Fig. 1). This study relates to the so-called Extended Hollo-bolt (EHB) blind-bolt (Fig. 2), which was developed as an experimental modification of the standard Hollo-bolt (HB) [2] at The University of Nottingham, UK [3].

The EHB fastener was developed specifically for use with concrete-filled hollow columns, where the infill is applied to the column in view of increasing the connection stiffness and strength by: 1) limiting the bending of the connected tube face, and 2) preventing bolt pullout from the development of mechanical anchorage on the column side [3, 4]. The 
performance of this innovative blind-bolting system has been studied under both monotonic [5] and quasi-static cyclic [6] loading in previous studies. The monotonic moment-rotation characteristics of the proposed technology have been assessed in accordance with the current connection classification system that is outlined in Eurocode 3 Part 1-8 [7]. In terms of stiffness, the tested connections were found to mostly exhibit semi-rigid behaviour for the relatively stiff connecting beam used; noting that none performed as a nominal pin. And analysis of normalised moment-rotation data with varying beam section sizes illustrated that in the case of using an extended endplate configuration, the connection can achieve rigid behaviour in braced frames [5]. When subjected to cyclic loading in accordance with the ECCS procedures [8], the proposed technology has demonstrated a high energy dissipation and ductility ratio, allowing for its use in moment-resisting frames that are designed for high ductility class in high seismic zones [6].

Structural joints, however, are not only subjected to a monotonic and/or cyclic increasing load. Commonly, steel structures are also subject to variable service loading, with most of the structural components being subjected to repeated fluctuating loads whose magnitude is well below the fracture load under monotonic loading [9]. When fluctuating loads are applied to a material, they may induce local stresses and strains which are sufficient to induce localised micro structural changes resulting in the development of cracks. This process is known as fatigue. The cracks, fatigue cracks, can grow to a size sufficient to cause failure [10]. And therefore, additionally, bolted connections require attention in terms of fatigue loading to prevent fatigue damage. Although not reported as frequently, one of the most common bolt failure mechanisms is fatigue [11]. Existing codes and standards that are typically applied in fatigue design, namely Eurocode 3 Part 1-9 [12] and ECCS [13], are based on nominal stress ranges and detail classification tables. These standards are applicable to conventional bolted connections, but their applicability has not been extended for the various blind-bolted 
connections. And due to the originality of the EHB fastening system, a fatigue design assessment for the EHB anchor blind-bolt has not yet been established.

It is the purpose of this paper to focus on the fatigue behaviour of this novel fastening system. The experimental programme is described in detail, and the experimental results are given in the form of stress range versus cycles to failure (S-N) plots. The results are discussed in terms of fatigue life, fatigue strength, and observed failure mode. The analysis concentrates on the influence of: 1) testing frequency, 2) level of loading (stress range), and 3) strength of concrete infill on the fatigue life of the blind-bolt system. A comparison of the fatigue behaviour among the $\mathrm{EHB}, \mathrm{HB}$ and traditional bolts is examined. Lastly, the EHB experimental S-N data is compared with the Eurocode 3 characteristic S-N curve, and the paper concludes on the performance of the novel blind-bolt under fatigue loading conditions in comparison with the fatigue behaviour of standard bolt-nut-washer systems.

\section{Experimental details}

\section{1 $\quad$ Test matrix}

The test matrix for the fatigue test series is summarised in Table 1, with each type of test bolt schematically shown in Fig. 3. Type HB involves the standard Hollo-bolt, type EHB involves the novel Extended Hollo-bolt, and type M represents a standard bolt-nut-washer system. The variables include: the stress range, $\Delta \sigma$ (from 45 to $90 \%$ of the design bolt stress); the grade of the concrete infill (C40 and C60); and the testing frequency (from 0.25 to $5 \mathrm{~Hz}$ ).

The aim of the tests was to establish the baseline for fatigue strength by evaluating the fatigue performance of the EHB blind-bolt. Further objectives were to determine a suitable testing frequency, and to investigate the influence of the infill strength on the fatigue life of the fastening system. 


\section{$2.2 \quad$ Test setup and loading}

To determine the fatigue behaviour of the EHB, a tensile, single bolt pull-out setup was adopted (Fig. 4). The setup consisted of a $30 \mathrm{~mm}$ thick, circular loading frame (to eliminate prying effects), that was connected to a relatively thick square hollow section (SHS) using either of the above mentioned test bolts (i.e. type HB, EHB, M). Upon tightening of the test bolts, the hollow sections were filled with concrete, and further tested under fatigue load once the nominal concrete strength was achieved. The thickness of the SHS was selected as such to minimise the bending of the SHS face.

All tests were conducted under load control - using the hydraulic (100 kN) Servocon system - adopting the loading protocol shown in Fig. 5; where the stress range is defined as the algebraic difference between the maximum and minimum stresses in a stress cycle. The different stress ranges $(\Delta \sigma)$ that were applied are outlined in Table 1 with respect to the nominal bolt design stress $\left(f_{y b}\right)$. An actual specimen ready for testing is presented in Fig. 6 .

\subsection{Material properties}

The properties for the internal bolts used in types $\mathrm{HB}$ and EHB, including the properties for those used in the testing of type $\mathrm{M}$ are summarised in Table 2. All test bolts were of property class 8.8 , had a nominal bolt diameter size of $16 \mathrm{~mm}$, and were tightened using a handheld torque wrench at $190 \mathrm{Nm}$. The strength of the concrete infill that was applied to the SHS test sections was determined by compressive cube $(100 \mathrm{~mm})$ testing. The actual strength for each corresponding specimen is included in Table 1; as measured on the day of testing. 


\section{Results and discussion}

\subsection{S-N data}

The experimental results for all of the tested bolt types are shown in Fig. 7 in the form of S-N diagrams; with the actual stress range $\left(\Delta \sigma_{\mathrm{a}}\right)$ being plotted on the y-axis while the number of cycles to failure $\left(\mathrm{N}_{\mathrm{f}}\right)$ are plotted along the $\mathrm{x}$-axis. Fig. 7a presents the results for type EHB with benchmark parameters (tests E1 to E30 in Table 1); designated EHB16-8.8-C40 (i.e. involving a $16 \mathrm{~mm}$ internal bolt diameter, of property class 8.8 , with a concrete infill of nominal grade $\mathrm{C} 40$ ). Fig. $7 \mathrm{~b}$ presents the $\mathrm{S}-\mathrm{N}$ data for type $\mathrm{EHB}$ when the nominal grade of the concrete infill increased to C60 (tests E31 to E36); designated EHB16-8.8-C60. Fig. 7c presents the test results for type $\mathrm{HB}$ (tests $\mathrm{H} 1$ to $\mathrm{H} 10$ ); designated HB16-8.8-C40. And the results for type $\mathrm{M}$ (tests $\mathrm{M} 1$ to M10) are shown in Fig. 7d; designated M16-8.8-C40. Similarly, for a clearer interpretation, the same $\mathrm{S}-\mathrm{N}$ data is shown in a normalised form in Fig. 8, with the actual stress range being normalised relative to the nominal yield strength of the test bolt.

The influence that the investigated stress ranges had on the fatigue life of the various test bolts is highlighted in the S-N data (i.e. Fig. 7 or Fig. 8). Notably, a consistent pattern is observed in the data. As anticipated, the fatigue life of type $\mathrm{EHB}, \mathrm{HB}$, and $\mathrm{M}$ increases as the applied stress range is decreased. Likewise, the number of cycles to failure decrease with an increase in the applied stress range. And in terms of repeatability, the test bolts exhibited a more stable fatigue life at the highest applied stress range (i.e. at $\Delta \sigma_{n} / f_{y b}=0.9$ ) in comparison with that which was recorded at the lower ranges (e.g. from $\Delta \sigma_{n} / f_{y b}=0.45$ to 0.70 ). A much higher degree of scatter is seen in the S-N data for these lower stress ranges.

For instance, at $\Delta \sigma_{n} / f_{y b}=0.9$ in Fig. $8 \mathrm{a}$, the EHB has demonstrated a fatigue life with a minimum difference of $15 \%$ among the repeated tests, despite the slight variation in their 
testing frequency. Whereas at the stress ranges of $\Delta \sigma_{n} / f_{y b}<0.9$, the number of cycles to failure for the EHB varied by more than $39 \%$ at least.

\subsection{Failure mode}

In general, a bolt fatigue failure involves three stages of damage: 1) crack initiation at a thread root, head-shank interface or material defect; 2) progressive cyclic fatigue growth; and 3) final sudden failure of the remaining cross-section of the bolt [11].

In this investigation, the failure mode of all the fatigue test specimens was found to be due to bolt shank fracture, with the fatigue failure occurring along the bolt, either within the clamping thickness (close to the first-engaged thread), or near the bolt head-to-shank radius. This failure mode was consistent throughout the testing programme for the various stress ranges that were applied. The location of fracture is distinguished in Table 1 for each test bolt. Images of the fractured bolts, and the typical, fracture surfaces that were identified in the testing of type EHB - in accordance with the applied stress range - are shown in Fig. 9 and Fig. 10, respectively.

The identified locations of fracture (i.e. along the shank at first-engaged threads or near the bolt head) are very common locations for fatigue crack initiation in bolts $[11,14]$, leading to fatigue failure. Although common, it should be recognised, that the identified fracture near the bolt head-to-shank radius could be indicating that either there is a manufacturing fault at this critical location, or that secondary bending forces may have been, undesirably, applied to the test bolts during the application of loading, which the bolt material was not able to withstand. 


\subsection{Testing frequency}

When performing fatigue tests, there is always a desire to reduce the testing duration as much as possible. This can be achieved by applying the highest test frequency possible, but it must be emphasised that restrictions can arise due to test equipment limitations (e.g. response time) and time-dependent processes. At the very early stages of this investigation, the appropriate testing frequency - particularly in combination with the available test equipment - was not well understood. Therefore, to determine the most suitable frequency - which would allow for a reasonable testing period, without inducing undesirable effects (e.g. such as hysteretic heating) - initially, the testing frequency was varied in the test series (from 0.25 to $5 \mathrm{~Hz}$, see test matrix in Table 1).

To evaluate the influence of the test frequencies adopted, the relationship obtained for the fatigue life and test frequency is plotted in Fig. 11 (for type EHB); with the measured number of cycles to failure being plotted on the dependent variable axis, and the test frequency being plotted along the independent variable axis. This diagram indicates that the studied range of test frequency can affect the fatigue life. This observation is principally shown in the data when $\Delta \sigma_{n} / f_{y b}=0.5$ and 0.9 , but partially evident in the case when $\Delta \sigma_{n} / f_{y b}=0.7$. When $\Delta \sigma_{n} /$ $f_{y b}=0.7$, the observation is partial because in the range of 1 to $3 \mathrm{~Hz}$, the fatigue life is seen to increase, but in contrast, from 3 to $5 \mathrm{~Hz}$, it is shown to decrease. It is additionally noted, however, that a common scatter is found in the fatigue life for the repeated tests, even at an identical frequency. For example, for the tests conducted at $2 \mathrm{~Hz}$, one test bolt endured approximately 0.26 million cycles, while the other only endured approximately 0.08 million cycles. And therefore, from this data analysis, the test frequency should not be linked directly with the fatigue life of the test bolt. 
A closer examination of the test results has revealed that the increase in the test frequency has mostly affected the actual applied stress range $\left(\Delta \sigma_{a}\right)$, rather than the fatigue life; a remark which is subject to the test equipment that was used in this study. To demonstrate this, using the same test series data (i.e. EHB16-8.8-C40), the actual applied stress range is charted versus the test frequency in Fig. 12. The chart shows the particular increase in $\Delta \sigma_{\mathrm{a}}$ when $\Delta \sigma_{n} /$ $f_{y b}=0.7$, justifying the reduction that was seen in the fatigue life when the test frequency was increased from 3 to $5 \mathrm{~Hz}$ in Fig. 11. It is anticipated that this increase in applied stress was a result of the acceleration in the hydraulic system when it was operating at a higher frequency. For this reason, $5 \mathrm{~Hz}$ was deemed unsatisfactory for the purposes of this testing, and was no longer considered. Instead, $3 \mathrm{~Hz}$ was deemed most appropriate, and was adopted throughout the remainder of the experimental study.

\subsection{Influence of concrete infill strength}

Previous work, regarding the structural behaviour of the EHB blind-bolt, has demonstrated that the grade of the hollow column concrete infill influences its response. The structural performance of type EHB was enhanced when its application was combined with higher concrete grade mixes. This observation is confirmed at a single component level of sophistication, i.e. in terms of the tensile force-deformability curve of the anchored fastener alone [15], and at an overall connection level, i.e. in terms of the moment-rotation characteristics of structural connections using type EHB [5]. This section will attempt to investigate the effect of increasing the concrete infill strength with respect to its fatigue performance.

Expectedly, the strength of the concrete material, on the day of testing, varied for the majority of the fatigue specimens; with various deviations from the nominal strength (see Table 1). Taking this into account, the effect of increasing the strength of the concrete infill on the 
fatigue life of the EHB is shown in Fig. 13; relating to stress ratios of 0.7 and 0.9 . The presented data relates to the tests designated E3, E4, E6, E9, E10 and E31 to E36. To account for the variability in the actual compressive strength of the infill on the day of testing $\left(f_{c u, a}\right)$, the number of cycles to failure, $\mathrm{N}_{\mathrm{f}}$ are normalised relative to the ratio of nominal to actual strength $\left(f_{c u, n} / f_{c u, a}\right)$, and further plotted versus the nominal concrete infill strength $\left(f_{c u, n}\right)$ in Fig. 13. The normalised chart indicates that a higher concrete grade improved the fatigue characteristics of the EHB. For both studied stress ratios (i.e. 0.7 and 0.9), there is a pattern of an increased fatigue life with the increase in compressive strength.

\subsection{Fatigue performance of tested bolt types}

The series of S-N data for the different types of test bolts are presented together in Fig. 14. This allows to compare, in a qualitative way, the fatigue behaviour of the EHB with that of standard bolts, as well as that of the standard HB. Within the tested range, compared with the standard HB, the EHB exhibits a higher fatigue life, but in comparison with standard bolts, the EHB exhibits a lower fatigue life. The data additionally highlights the influence of the additional mechanical anchorage that is provided in the load transfer mechanism of the EHB. This is seen by the improvement in the fatigue characteristics of type EHB in comparison with those of the standard HB.

For a clearer interpretation of the comparison among the tested types of bolting systems, the S-N data is re-arranged in the form of fatigue life against nominal stress ratio (Fig. 15). For both stress ratios (i.e. 0.7 and 0.9 ), it is found that the fatigue performance of the standard bolt (i.e. type M, designated M16-8.8-C40) is superior to that exhibited by the EHB and standard HB. Notably, however, approaching the nominal yielding, at $\Delta \sigma_{n} / f_{y b}=0.9$, the fatigue life of the three test bolts appears to converge. 


\subsection{Eurocode 3 characteristic $S-N$ curve}

To assess the performance of the EHB blind-bolt subject to fatigue loading conditions, a fatigue assessment is carried out in accordance with EC3 Part 1-9 [12]. The assessment is based on the fatigue strength curve of the direct stress range for the various detail categories that are provided in the code. Principally, the fatigue strength curve varies, depending on the so-called detail category $\left(\Delta \sigma_{c}\right)$. To allow for fatigue assessment, different constructional details (e.g. bolts in tension) are allocated within a detail category (e.g. Category 50). Having defined the detail category, the EC3 fatigue strength curve can be determined using the below formulae, combined with the notation chart shown in Fig. 16.

when $\mathrm{N} \leq 5 \times 10^{6}$ :

$\Delta \sigma_{\mathrm{R}}=\Delta \sigma_{\mathrm{C}}\left[\left(2 \times 10^{6}\right) / \mathrm{N}\right]^{1 / \mathrm{m}}$, and $\mathrm{m}=3$,

hence:

$\Delta \sigma \mathrm{D}=\Delta \sigma \mathrm{C}(2 / 5)^{1 / 3}$

when $5 \times 10^{6} \leq \mathrm{N} \leq 10^{8}$ :

$\Delta \sigma_{\mathrm{R}}=\Delta \sigma_{\mathrm{D}}\left[\left(5 \times 10^{6}\right) / \mathrm{N}\right]^{1 / \mathrm{m}}$, and $\mathrm{m}=5$,

hence:

$\Delta \sigma_{\mathrm{L}}=\Delta \sigma_{\mathrm{D}}(5 / 100)^{1 / 5}$

where: $\Delta \sigma_{\mathrm{D}}$ is the constant amplitude fatigue limit and $\Delta \sigma_{\mathrm{L}}$ is the cut off limit.

The cut off limit is the limit below which stress ranges of the design spectrum do not contribute to the calculated cumulative damage. The constant amplitude fatigue limit is the limiting direct stress range value below which no fatigue damage will occur in tests under constant amplitude stress conditions. For example, if $\Delta \sigma_{\mathrm{D}}$ is equal to $20 \mathrm{~N} / \mathrm{mm}^{2}$, this means 
that, for a constant amplitude loading, there is no fatigue damage where the stress range is less than $20 \mathrm{~N} / \mathrm{mm}^{2}$.

For the purposes of this assessment, the EC3 detail Category 50 is implemented, which is the current category in which standard bolting systems (in tension) are included. The type EHB experimental S-N data is presented in Fig. 17, alongside the reference fatigue strength curve corresponding to detail Category 50. Within the investigated range, it is found that the test data lies above the EC3 curve, indicating that the results satisfy the theoretical design curve that is suggested for standard bolts, such as type M. Hence the fatigue performance of the EHB anchored blind-bolt can be said to be adequately represented by the existing EC3 detail Category 50.

\section{Concluding remarks}

This paper has presented the experimental results, of a programme, that was conducted to investigate the fatigue behaviour of a novel anchored blind-bolt; the so-called Extended Hollo-bolt (EHB). The application of the fastening system relates to the construction of bolted, moment-resisting connections to concrete-filled hollow section columns.

Fatigue tests, for three different types of test bolts, were performed for varying stress ranges, under constant amplitude loading conditions, and the resulting S-N data was analysed. The expected pattern of stress range versus fatigue life relationships were achieved, with the higher amplitude tests exhibiting a smaller number of cycles to failure compared with the lower amplitude tests.

The influence of test frequency and concrete strength were examined. In consideration of the employed test equipment, a frequency of $3 \mathrm{~Hz}$ was found to be most suitable for the loading protocol that was adopted in the fatigue tests. In the cases where the adopted magnitude of 
test frequency was higher than $3 \mathrm{~Hz}$, undesirable changes were observed in the applied stress range. Experimental evidence indicated that the fatigue life of the EHB blind-bolt can increase in the case of increasing the strength of the hollow column concrete infill.

The experimental S-N data for the EHB blind-bolt were compared with that of the standard HB blind-bolt, and that of a standard bolt type, and a fatigue assessment of the data was performed in accordance with the Eurocode 3 guidelines. The fatigue performance of the tested bolts was found to be comparable among each other at stress ratios close to the nominal yield strength of the bolt material. For reference, the EC3 Part 1-9 characteristic fatigue strength curve, corresponding to detail Category 50 for standard bolts in tension, was used to assess the fatigue performance of the EHB anchored blind-bolt. The fatigue design strength of the single EHB anchor blind-bolt was found to be adequately represented by the current fatigue specification detail Category 50; showing that the fatigue performance of the EHB satisfies the existing rules that are used for standard bolt-nut-washer systems.

Overall, this paper has generated sufficient fatigue test data that can be used to perform a statistical estimation for the linear (log-log) S-N curve fit of type EHB, including the relevant reliability analysis to determine the tolerance limits, confidence intervals, safety index and corresponding probability of failure; which is the subject of on-going work.

\section{Acknowledgements}

The authors wish to acknowledge Tata Steel (formally Corus) and Lindapter International ${ }^{\circledR}$ for supporting this research work. Gratitude is expressed to Mr Trevor Mustard, of TATA Steel, and Mr Neil Gill, of Lindapter International. The second author would also like to thank the Ministry of Higher Education of Malaysia for their financial support. 


\section{Tables}

Table 1. Test matrix

\begin{tabular}{|c|c|c|c|c|c|c|c|c|c|}
\hline $\begin{array}{l}\text { Sample } \\
\text { index }\end{array}$ & $\begin{array}{c}\Delta \sigma_{n} \\
\left(\mathrm{~N} / \mathrm{mm}^{2}\right)\end{array}$ & $\begin{array}{c}f_{c u, n} \\
\left(\mathrm{~N} / \mathrm{mm}^{2}\right)\end{array}$ & $\Delta \sigma_{n} / f_{y b}$ & $\begin{array}{c}\Delta \sigma_{a} \\
\left(\mathrm{~N} / \mathrm{mm}^{2}\right) \\
\end{array}$ & $\begin{array}{c}f_{c u, a} \\
\left(\mathrm{~N} / \mathrm{mm}^{2}\right)^{a}\end{array}$ & $\Delta \sigma_{a} / f_{y b}$ & $\begin{array}{c}\text { Frequency } \\
(\mathrm{Hz})\end{array}$ & Failure mode & Cycles to failure, $N_{f}$ \\
\hline \multicolumn{10}{|l|}{ Tуре EHB } \\
\hline E1 & 584 & 40 & 0.91 & 582 & 35.8 & 0.91 & 0.25 & Bolt fracture (shank) & 8025 \\
\hline E2 & 584 & 40 & 0.91 & 583 & 42.5 & 0.91 & 1.0 & Bolt fracture (shank) & 9314 \\
\hline E3 & 584 & 40 & 0.91 & 583 & 40.3 & 0.91 & 3.0 & Bolt fracture (shank) & 10489 \\
\hline E4 & 584 & 40 & 0.91 & 585 & 40.3 & 0.91 & 3.0 & Bolt fracture (near head) & 12063 \\
\hline E5 & 454 & 40 & 0.71 & 454 & 35.9 & 0.71 & $0.25-1.0$ & Bolt fracture (shank) & 20608 \\
\hline E6 & 454 & 40 & 0.71 & 459 & 41.0 & 0.72 & 3.0 & Bolt fracture (near head) & 45631 \\
\hline E7 & 454 & 40 & 0.71 & 494 & 41.0 & 0.77 & 5.0 & Bolt fracture (near head) & 20649 \\
\hline E8 & 454 & 40 & 0.71 & 496 & 38.7 & 0.77 & 5.0 & Bolt fracture (near head) & 21441 \\
\hline E9 & 454 & 40 & 0.71 & 467 & 41.0 & 0.73 & 3.0 & Bolt fracture (shank) & 28331 \\
\hline E10 & 454 & 40 & 0.71 & 479 & 41.0 & 0.75 & 3.0 & Bolt fracture (shank) & 28632 \\
\hline E11 & 389 & 40 & 0.61 & 393 & 40.0 & 0.61 & $1.0-2.0$ & Bolt fracture (shank) & 55822 \\
\hline E12 & 389 & 40 & 0.61 & 399 & 37.4 & 0.62 & 3.0 & Bolt fracture (near head) & 40297 \\
\hline E13 & 389 & 40 & 0.61 & 393 & 41.9 & 0.61 & 3.0 & Bolt fracture (near head) & 191710 \\
\hline E14 & 389 & 40 & 0.61 & 395 & 41.8 & 0.62 & 3.0 & Bolt fracture (shank) & 126731 \\
\hline E15 & 389 & 40 & 0.61 & 397 & 42.5 & 0.62 & 3.0 & Bolt fracture (near head) & 202742 \\
\hline E16 & 389 & 40 & 0.61 & 398 & 40.3 & 0.62 & 3.0 & Bolt fracture (shank) & 107526 \\
\hline E17 & 389 & 40 & 0.61 & 391 & 41.2 & 0.61 & 3.0 & Bolt fracture (near head) & 313697 \\
\hline E18 & 389 & 40 & 0.61 & 395 & 39.3 & 0.62 & 3.0 & Bolt fracture (shank) & 58142 \\
\hline E19 & 389 & 40 & 0.61 & 395 & 37.6 & 0.62 & 3.0 & Bolt fracture (shank) & 63314 \\
\hline E20 & 324 & 40 & 0.51 & 330 & 43.6 & 0.52 & 2.0 & Bolt fracture (near head) & 264135 \\
\hline E21 & 324 & 40 & 0.51 & 332 & 37.4 & 0.52 & 3.0 & Bolt fracture (shank) & 89300 \\
\hline $\mathrm{E} 22$ & 324 & 40 & 0.51 & 330 & 40.9 & 0.52 & 3.0 & Bolt fracture (near head) & 91878 \\
\hline E23 & 324 & 40 & 0.51 & 324 & 41.2 & 0.51 & 2.0 & Bolt fracture (shank) & 78803 \\
\hline E24 & 324 & 40 & 0.51 & 331 & 41.2 & 0.52 & 3.0 & Bolt fracture (shank) & 450044 \\
\hline E25 & 324 & 40 & 0.51 & 332 & 42.7 & 0.52 & 3.0 & Bolt fracture (shank) & 626804 \\
\hline E26 & 292 & 40 & 0.46 & 292 & 40.0 & 0.46 & $1.0-2.0$ & Bolt fracture (near head) & 1328102 \\
\hline $\mathrm{E} 27$ & 292 & 40 & 0.46 & 300 & 39.3 & 0.47 & 3.0 & Bolt fracture (near head) & 3358810 \\
\hline E28 & 292 & 40 & 0.46 & 311 & 38.7 & 0.49 & 3.0 & Bolt fracture (shank) & 2012778 \\
\hline E29 & 292 & 40 & 0.46 & 299 & 38.5 & 0.47 & 3.0 & Bolt fracture (shank) & 676386 \\
\hline
\end{tabular}


Table 1. (continued)

\begin{tabular}{|c|c|c|c|c|c|c|c|c|c|}
\hline $\begin{array}{l}\text { Sample } \\
\text { index }\end{array}$ & $\begin{array}{c}\Delta \sigma_{n} \\
\left(\mathrm{~N} / \mathrm{mm}^{2}\right)\end{array}$ & $\begin{array}{c}f_{c u, n} \\
\left(\mathrm{~N} / \mathrm{mm}^{2}\right)\end{array}$ & $\Delta \sigma_{n} / f_{y b}$ & $\begin{array}{c}\Delta \sigma_{a} \\
\left(\mathrm{~N} / \mathrm{mm}^{2}\right)\end{array}$ & $\begin{array}{c}f_{\text {cu,a }} \\
\left(\mathrm{N} / \mathrm{mm}^{2}\right)^{a}\end{array}$ & $\Delta \sigma_{a} / f_{y b}$ & $\begin{array}{c}\text { Frequency } \\
(\mathrm{Hz})\end{array}$ & Failure mode & Cycles to failure, $N_{f}$ \\
\hline E30 & 292 & 40 & 0.46 & 298 & 38.1 & 0.46 & 3.0 & Bolt fracture (shank) & 528703 \\
\hline E31 & 584 & 60 & 0.91 & 589 & 64.5 & 0.92 & 3.0 & Bolt fracture (near head) & 13840 \\
\hline E32 & 584 & 60 & 0.91 & 586 & 64.5 & 0.92 & 3.0 & Bolt fracture (near head) & 21624 \\
\hline E33 & 584 & 60 & 0.91 & 584 & 62.3 & 0.91 & 3.0 & Bolt fracture (shank) & 17707 \\
\hline E34 & 454 & 60 & 0.71 & 460 & 59.8 & 0.72 & 3.0 & Bolt fracture (shank) & 27919 \\
\hline E35 & 454 & 60 & 0.71 & 456 & 59.8 & 0.71 & 3.0 & Bolt fracture (shank) & 42862 \\
\hline E36 & 454 & 60 & 0.71 & 459 & 62.3 & 0.72 & 3.0 & Bolt fracture (near head) & 88765 \\
\hline \multicolumn{10}{|l|}{ Type $H B$} \\
\hline $\mathrm{H} 1$ & 584 & 40 & 0.91 & 579 & 38.0 & 0.90 & 3.0 & Bolt fracture (near head) & 12174 \\
\hline $\mathrm{H} 2$ & 584 & 40 & 0.91 & 577 & 38.0 & 0.90 & 3.0 & Bolt fracture (near head) & 10756 \\
\hline H3 & 454 & 40 & 0.71 & 449 & 37.6 & 0.70 & 3.0 & Bolt fracture (near head) & 20817 \\
\hline $\mathrm{H} 4$ & 454 & 40 & 0.71 & 450 & 38.8 & 0.70 & 3.0 & Bolt fracture (near head) & 20034 \\
\hline H5 & 389 & 40 & 0.61 & 390 & 38.8 & 0.61 & 3.0 & Bolt fracture (near head) & 29779 \\
\hline H6 & 389 & 40 & 0.61 & 391 & 38.8 & 0.61 & 3.0 & Bolt fracture (near head) & 38491 \\
\hline $\mathrm{H} 7$ & 324 & 40 & 0.51 & 323 & 39.3 & 0.50 & 3.0 & Bolt fracture (near head) & 110000 \\
\hline H8 & 324 & 40 & 0.51 & 321 & 39.3 & 0.50 & 3.0 & Bolt fracture (near head) & 39671 \\
\hline H9 & 324 & 40 & 0.51 & 327 & 39.8 & 0.51 & 3.0 & Bolt fracture (near head) & 60577 \\
\hline $\mathrm{H} 10$ & 324 & 40 & 0.51 & 326 & 39.8 & 0.51 & 3.0 & Bolt fracture (near head) & 62401 \\
\hline \multicolumn{10}{|l|}{ Tyре $M$} \\
\hline M1 & 584 & 40 & 0.91 & 577 & 36.9 & 0.90 & 3.0 & Bolt fracture (shank) & 16957 \\
\hline M2 & 584 & 40 & 0.91 & 578 & 36.9 & 0.90 & 3.0 & Bolt fracture (shank) & 14806 \\
\hline M3 & 584 & 40 & 0.91 & 577 & 39.4 & 0.90 & 3.0 & Bolt fracture (shank) & 17020 \\
\hline M4 & 519 & 40 & 0.81 & 516 & 41.9 & 0.81 & 3.0 & Bolt fracture (near head) & 80293 \\
\hline M5 & 519 & 40 & 0.81 & 517 & 41.9 & 0.81 & 3.0 & Bolt fracture (shank) & 14018 \\
\hline M6 & 519 & 40 & 0.81 & 521 & 41.2 & 0.81 & 3.0 & Bolt fracture (shank) & 32193 \\
\hline M7 & 519 & 40 & 0.81 & 521 & 41.2 & 0.81 & 3.0 & Bolt fracture (shank) & 27514 \\
\hline M8 & 454 & 40 & 0.71 & 454 & 36.8 & 0.71 & 3.0 & Bolt fracture (shank) & 320684 \\
\hline M9 & 454 & 40 & 0.71 & 455 & 38.2 & 0.71 & 3.0 & Bolt fracture (shank) & 254351 \\
\hline M10 & 454 & 40 & 0.71 & 457 & 39.4 & 0.71 & 3.0 & Bolt fracture (shank) & 300387 \\
\hline
\end{tabular}

$\Delta \sigma$ is the stress range; subscripts $\mathrm{n}_{\mathrm{n}}$ and ${ }_{\mathrm{a}}$ designate the nominal and actual values, respectively; $f_{\mathrm{yb}}$ is the nominal yield strength. 
Table 2. Bolt properties

\begin{tabular}{lcccccc}
\hline Type & $\begin{array}{c}d_{b} \\
(\mathrm{~mm})\end{array}$ & Property class & $\begin{array}{c}f_{y b} \\
\left(\mathrm{~N} / \mathrm{mm}^{2}\right)\end{array}$ & $\begin{array}{c}f_{y b, a} \\
\left(\mathrm{~N} / \mathrm{mm}^{2}\right)\end{array}$ & $\begin{array}{c}f_{u b, a} \\
\left(\mathrm{~N} / \mathrm{mm}^{2}\right)\end{array}$ & $\begin{array}{c}E_{b} \\
\left(\mathrm{kN} / \mathrm{mm}^{2}\right)\end{array}$ \\
\hline EHB & 16 & 8.8 & 640 & 813 & 852 & 205 \\
HB & 16 & 8.8 & 640 & 816 & 967 & 209 \\
M & 16 & 8.8 & 640 & 851 & 925 & 208 \\
\hline
\end{tabular}

$d_{b}$ is the nominal bolt diameter size; $f_{v b}$ is the nominal yield strength;

$f_{y b, a}$ and $f_{u b, a}$ are the actual yield and ultimate strength; $E_{b}$ is Young's Modulus of Elasticity; 


\section{Figures}

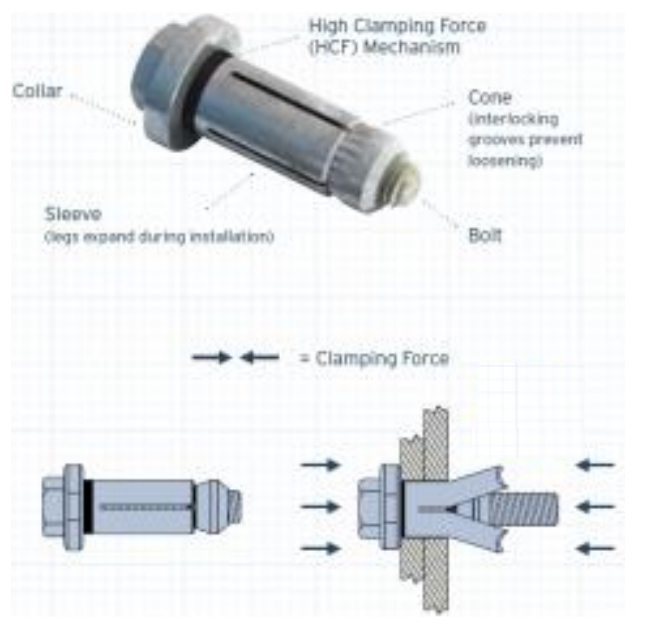

Fig. 1. The Lindapter Hollo-bolt blind-bolt [2]

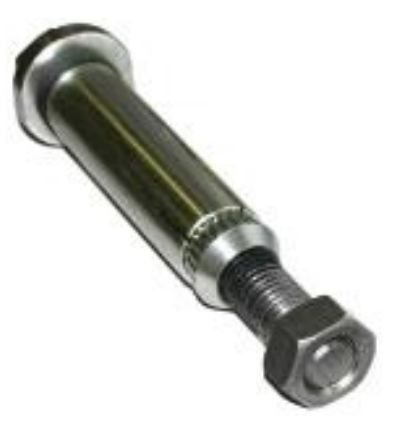

Fig. 2. The Extended Hollo-bolt (EHB)
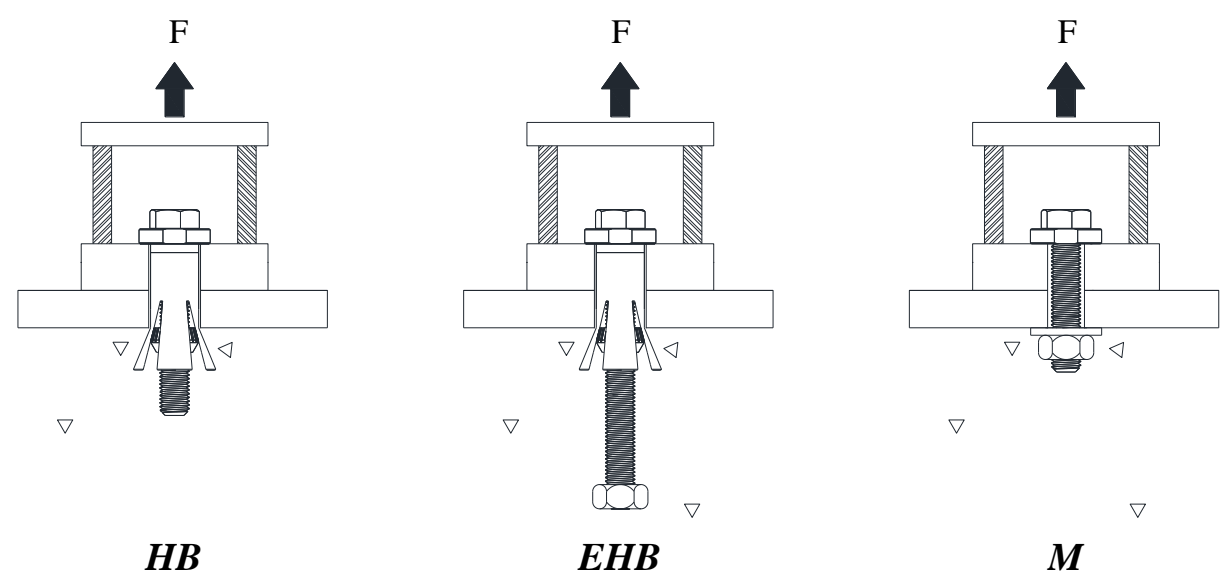

Fig. 3. Test bolt types 


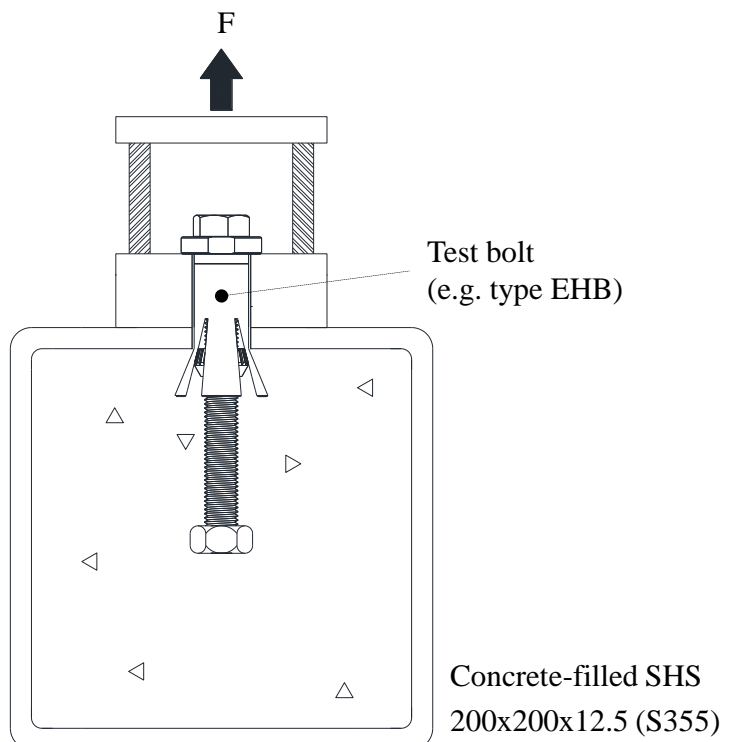

Fig. 4. Fatigue pull-out test setup

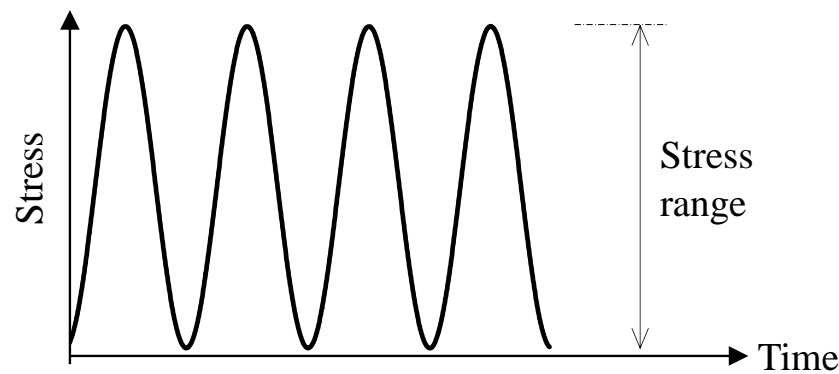

Fig. 5. Loading procedure

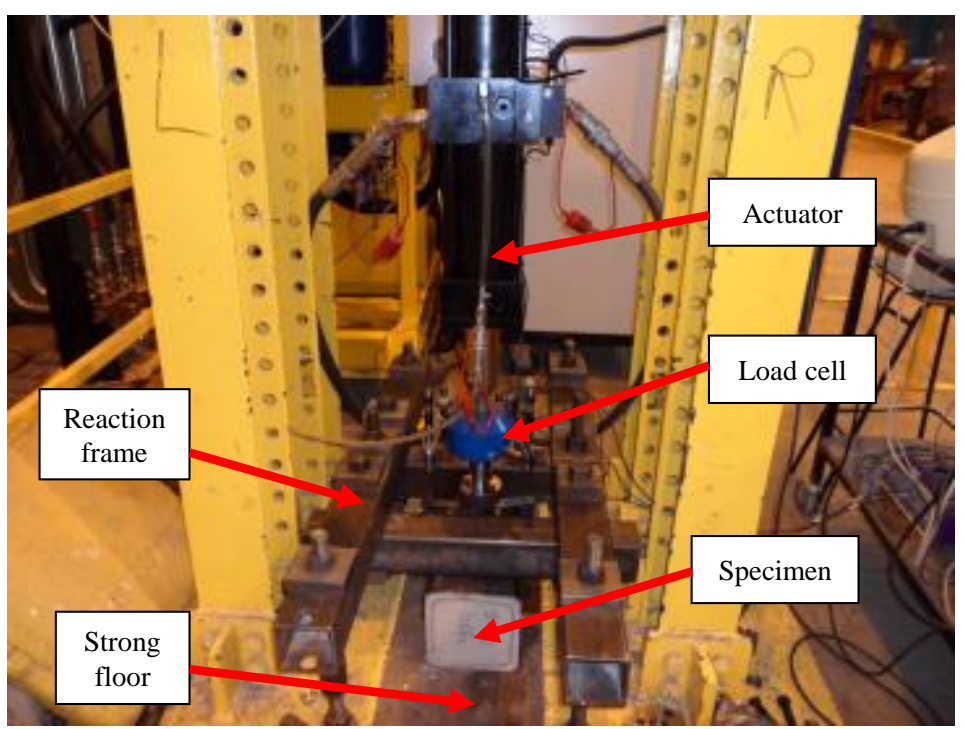

Fig. 6. Specimen ready for fatigue testing 

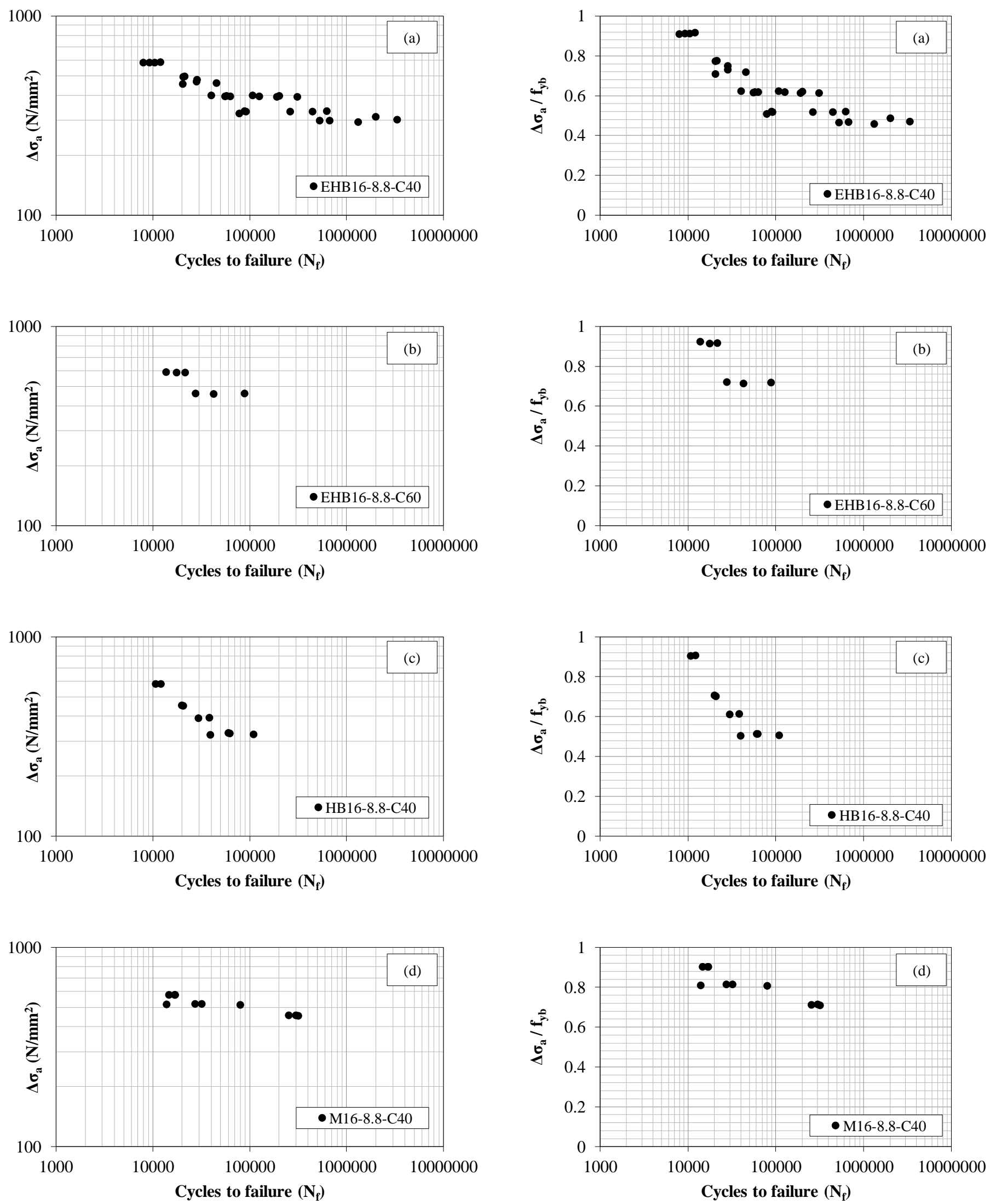

Fig. 7. Experimental S-N data

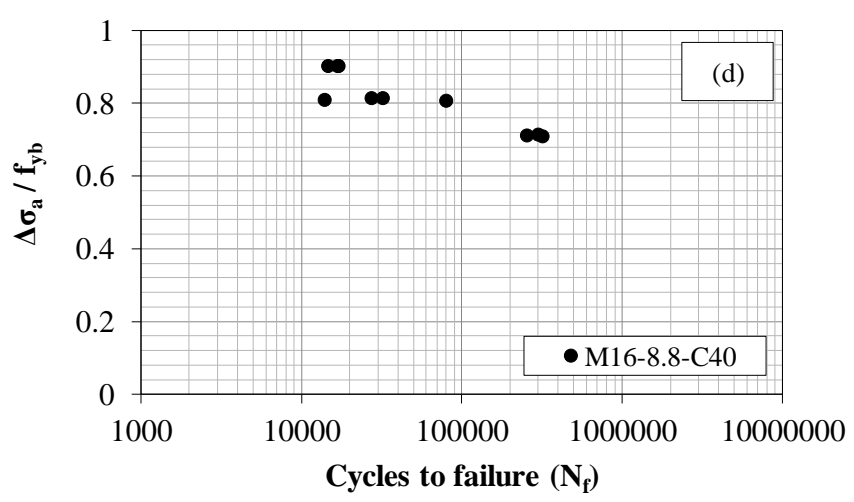

Fig. 8. Experimental S-N data (normalised) 

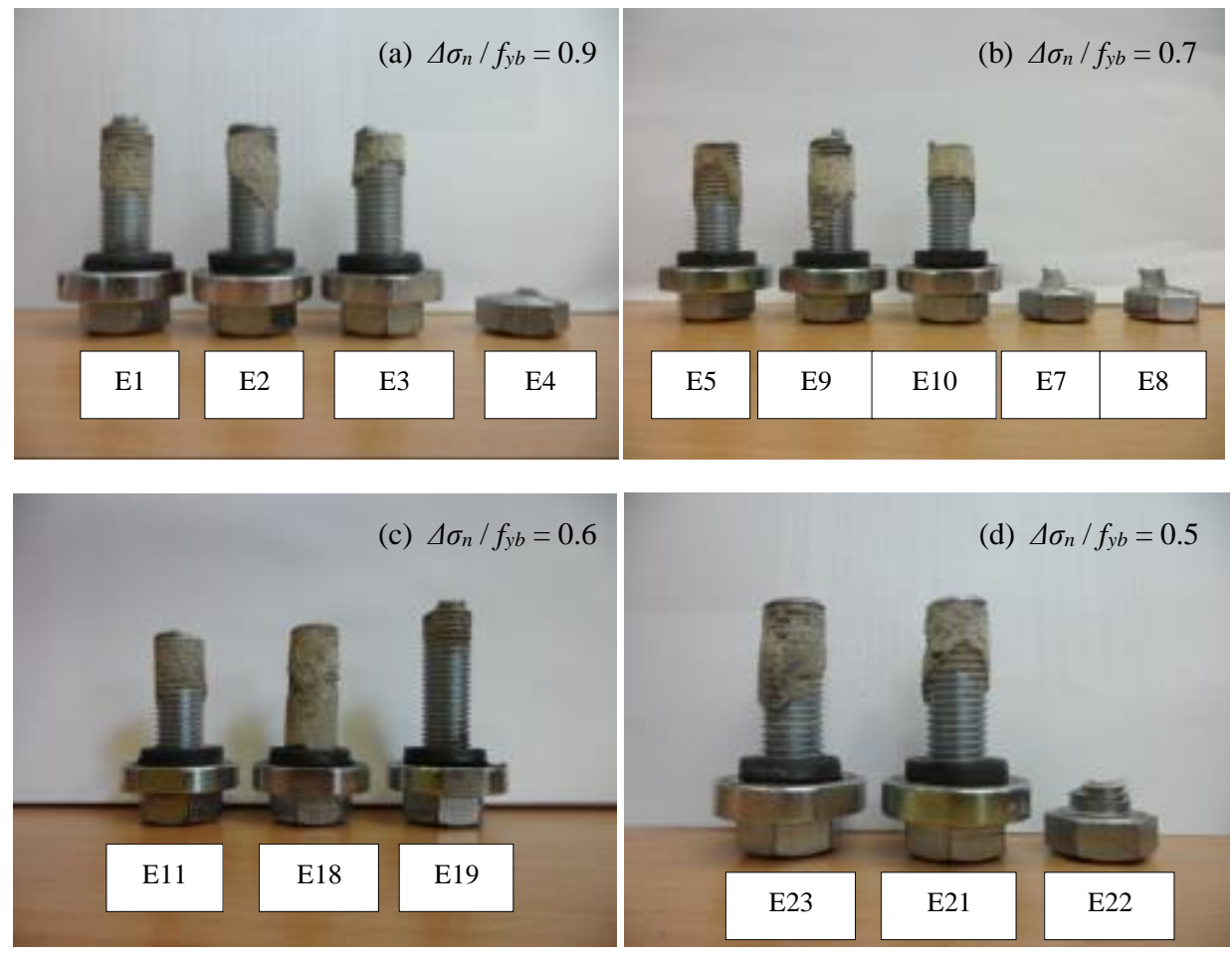

Fig. 9. Failure mode of Extended Hollo-bolt

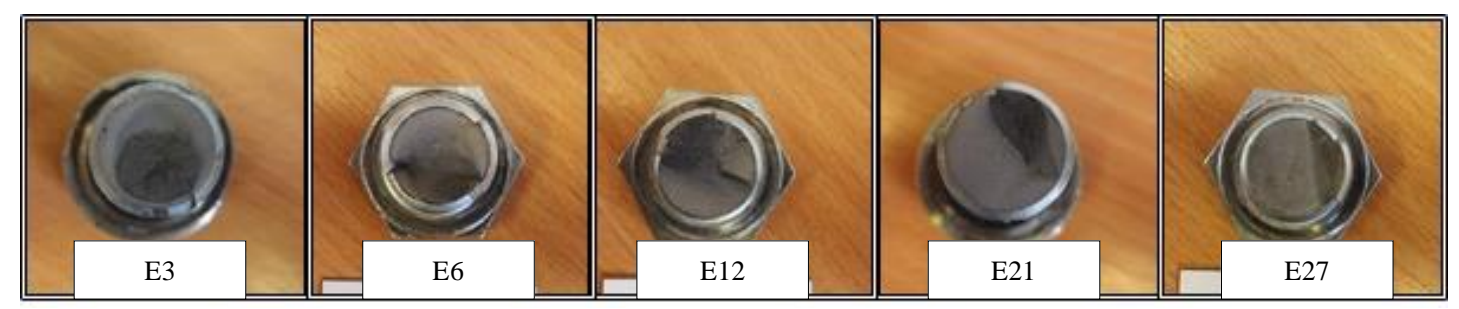
(a) $\Delta \sigma_{n} / f_{y b}=0.9$
(b) $\Delta \sigma_{n} / f_{y b}=0.7$
(c) $\Delta \sigma_{n} / f_{y b}=0.6$
(d) $\Delta \sigma_{n} / f_{y b}=0.5$
(e) $\Delta \sigma_{n} / f_{y b}=0.45$

Fig. 10. Fracture surface of Extended Hollo-bolt

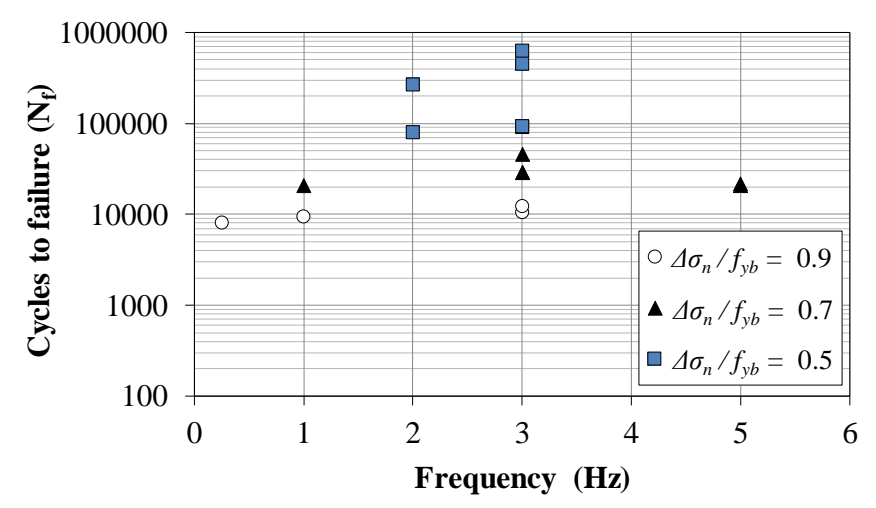

Fig. 11. Influence of testing frequency (EHB16-8.8-C40)

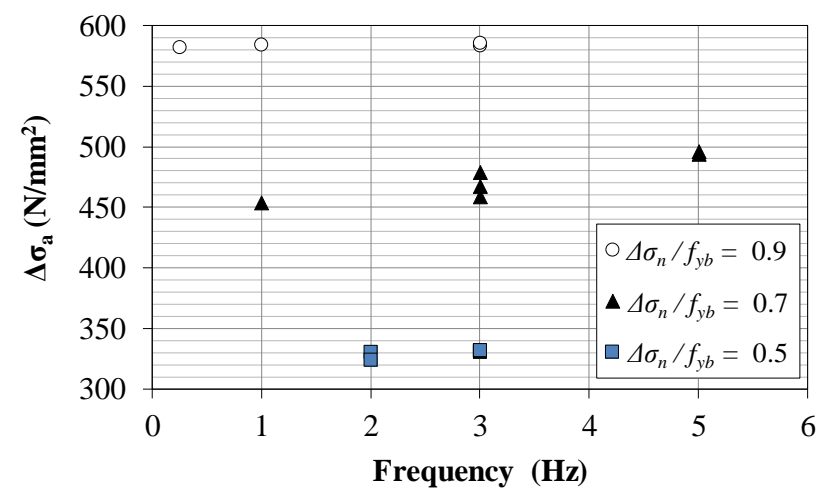

Fig. 12. Effect of test frequency on actual stress range 


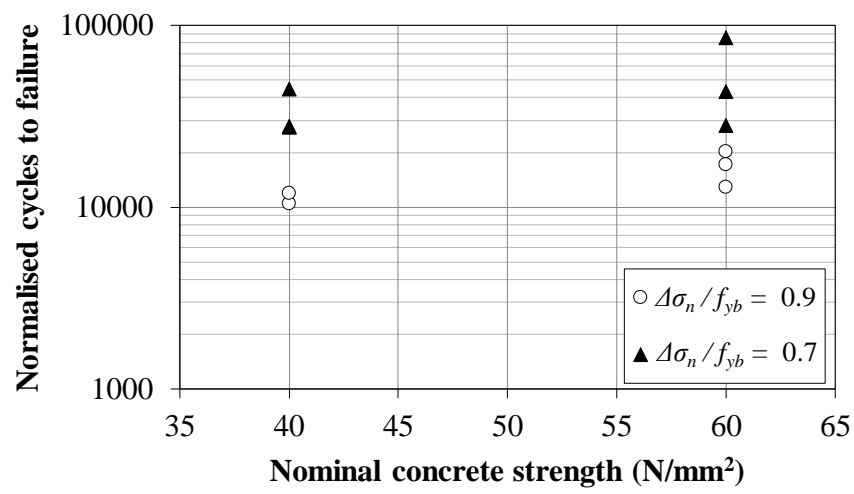

Fig. 13. Influence of concrete strength on fatigue life of Extended Hollo-bolt

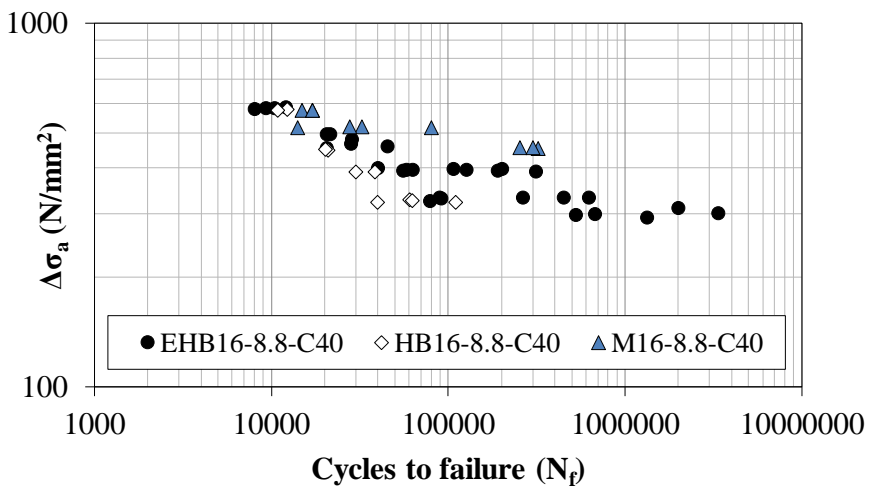

Fig. 14. Comparison of experimental S-N data among test bolt types



Endurance, number of cycles (N)

Fig. 16. EC3 Part 1-9 fatigue strength curve [12]

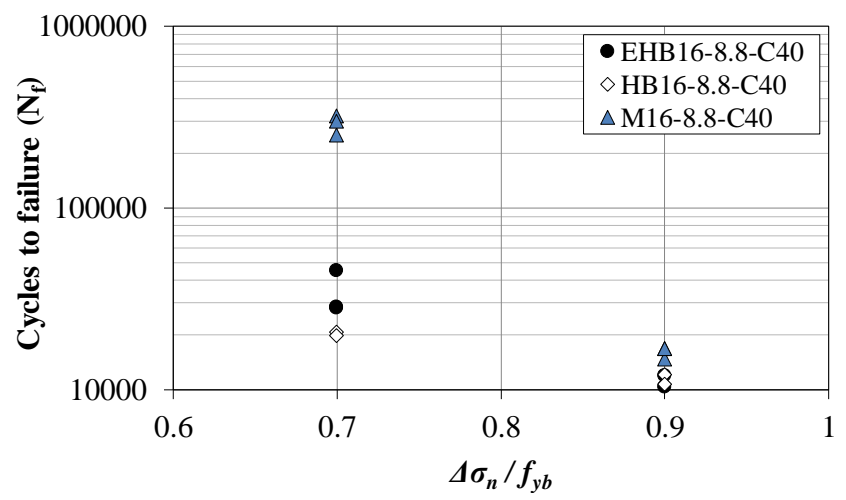

Fig. 15. Fatigue life of tested bolt types

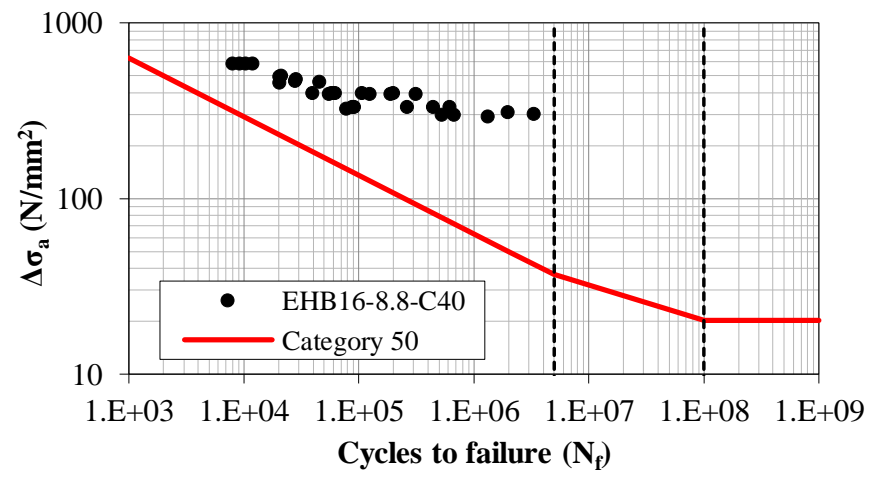

Fig. 17. Fatigue assessment of S-N data to EC3 


\section{References}

[1] Wardenier J, Packer J, Zhao, X-L, Vegte, G.J. van der. Hollow sections in structural applications (2nd edition). CIDECT, Geneva, Switzerland; 2010.

[2] Lindapter. Type HB - Hollo-Bolt. Cavity Fixings 2, Product Brochure: Lindapter International, UK; 2012. p. 41-3. Available at:

http://www.lindapter.com/products/Cavity_Fixings/2/Type_HB_Hollo-Bolt (last accessed: 01 Nov 2012).

[3] Tizani W, Ridley-Ellis DJ. The performance of a new blind-bolt for moment-resisting connections. In: Jaurietta, MA, Alonso, A, Chica, JA (eds), Tubular structures X: Proceedings of the 10th international symposium on tubular structures, AA Balkema 2003. p. 395-400.

[4] Ellison S, Tizani W. Behaviour of blind bolted connections to concrete filled hollow sections. The Structural Engineer. 2004;82:16-7.

[5] Tizani W, Al-Mughairi A, Owen JS, Pitrakkos T. Rotational stiffness of a blind-bolted connection to concrete-filled tubes using modified Hollo-bolt. Journal of Constructional Steel Research. 2013;80:317-31.

[6] Tizani W, Wang ZY, Hajirasouliha I. Hysteretic performance of a new blind bolted connection to concrete filled columns under cyclic loading: An experimental investigation. Engineering Structures. 2013;46:535-46.

[7] CEN. Eurocode 3: Design of steel structures - Part 1-8: Design of joints. BS EN 1993-1-8:2005, British Standards Institution; 2005.

[8] ECCS. Technical Committee 1: structural safety and loadings: technical working group 1.3: seismic design, recommended testing procedure for assessing the behaviour of structural steel elements under cyclic loads. 1986.

[9] Barsom JM, Rolfe ST. Fracture and fatigue control in structures: applications of fracture mechanics: (MNL 41), Third edition: ASTM International; 1999.

[10] Wingerde, A.M. van. The fatigue behaviour of T- and X-joints made of square hollow sections. HERON. 1992;37.

[11] Benac DJ. Technical Brief: Avoiding Bolt Failures. Journal of Failure Analysis and Prevention. 2007;7:79-80.

[12] CEN. Eurocode 3: Design of steel structures - Part 1-9: Fatigue. BS EN 1993-1-9:2005, British Standards Institution; 2005.

[13] ECCS. Recommendation for the fatigue design of steel structures. European Convention for Constructional Steelwork. 1985.

[14] Bickford JH. Introduction to the Design and Behavior of Bolted Joints , Fourth Edition, NonGasketed Joints, Taylor \& Francis Group. 2008.

[15] Pitrakkos T, Tizani W. Experimental behaviour of a novel anchored blind-bolt in tension.

Engineering Structures. 2013;49:905-19. 